\title{
Zika virus challenges for neuropsychiatry
}

This article was published in the following Dove Press journal:

Neuropsychiatric Disease and Treatment

I 4 July 2016

Number of times this article has been viewed

\author{
Ana Cristina Simões e Silva ${ }^{1,2}$ \\ Janaina Matos Moreira ${ }^{1,2}$ \\ Roberta Maia Castro \\ Romanelli2 \\ Antonio Lucio Teixeira ${ }^{1,3}$ \\ 'Interdisciplinary Laboratory of \\ Medical Investigation, ${ }^{2}$ Department \\ of Pediatrics, Faculty of Medicine, \\ Federal University of Minas Gerais \\ (UFMG), Belo Horizonte, Brazil; \\ ${ }^{3}$ Neuropsychiatry Program, \\ Department of Psychiatry and \\ Behavioral Sciences, McGovern \\ Medical School, University of Texas \\ Health Science Center at Houston, \\ Houston, TX, USA
}

\begin{abstract}
Before 2007, Zika virus (ZIKV) was generally considered as an arbovirus of low clinical relevance, causing a mild self-limiting febrile illness in tropical Africa and Southeast Asia. Currently, a large, ongoing outbreak of ZIKV that started in Brazil in 2015 is spreading across the Americas. Virus infection during pregnancy has been potentially linked to congenital malformations, including microcephaly. In addition to congenital malformations, a temporal association between ZIKV infection and an increase in cases of Guillain-Barré syndrome is currently being observed in several countries. The mechanisms underlying these neurological complications are still unknown. Emerging evidence, mainly from in vitro studies, suggests that ZIKV may have direct effects on neuronal cells. The aim of this study was to critically review the literature available regarding the neurobiology of ZIKV and its potential neuropsychiatric manifestations.
\end{abstract}

Keywords: Zika virus, microcephaly, Guillain-Barré syndrome, neurodevelopmental disorders

\section{Introduction}

Zika virus (ZIKV) is an arthropod-borne virus (arbovirus) transmitted by Aedes spp. In recent years, outbreaks of ZIKV infection have occurred, and the infection has been linked to severe neurological complications, including microcephaly and GuillainBarré syndrome (GBS).

In this article, we first briefly review the biology and epidemiology of ZIKV and then critically address the literature available regarding the neurobiology of ZIKV and its potential neuropsychiatric manifestations.

\section{Virology of ZIKV}

ZIKV is a positive single-strand enveloped RNA virus that belongs to the family Flaviviridae and genus Flavivirus. ZIKV genome includes two noncoding regions and one region encoding a polyprotein that is cleaved into capsid, membrane precursor, and envelope, and also seven nonstructural proteins. ${ }^{1,2}$ Based on the phylogenetic tree reported by Weaver et al, ${ }^{3} \mathrm{ZIKV}$ differs from other Flavivirus by $20 \%$ nucleotide sequence divergence.

The prototype ZIKV MR 766 was first identified in Africa. ${ }^{4-7}$ In Asia, Lanciotti et al $^{8}$ described a coding region of ZIKV 2007 EC and the nonstructural protein 5 (NS5) gene, corresponding to a Flavivirus sequence, showing a high homology of the Asian strain with the virus originally identified in Africa. Accordingly, it has been proposed that the Asian cluster was phylogenetically derived from the African ZIKV strain. ${ }^{2,8,9}$ The first cases of ZIKV infection reported in Brazil were from a strain genetically related to the Asian lineage. ${ }^{10-12}$ The introduction of ZIKV in Brazil probably occurred in 2014 due to the arrival of foreign tourists and athletes during the Soccer World 
Cup and/or other sport events. ${ }^{11,12}$ Giovanetti et al ${ }^{13}$ described the complete genome of ZIKV isolated in Brazil, confirming that this cluster is similar to the virus isolated in French Polynesia. $^{13,14}$

\section{Early studies and epidemiology of ZIKV}

The denomination Zika came from a forested area in Uganda, where ZIKV was first identified in rhesus monkeys during a research about yellow fever cycle and other arboviruses. ${ }^{5}$ The virus was also identified in mosquitoes., ${ }^{4,6}$ Later, Boorman and Poeterfield ${ }^{15}$ proved the transmission from laboratory-infected Aedes aegypti mosquitoes to rhesus monkeys. Simpson ${ }^{16}$ reported the first proved case of vector transmission and human disease.

Dick $^{6}$ inoculated ZIKV in mice and detected virus replication in the brain. Some mice exhibited motor weakness and paralysis, and susceptibility to infection appeared to decrease with age. Therefore, ZIKV was considered neurotropic since its original description.

The first evidence of human infection based on the identification of antibodies against ZIKV came from patients in Uganda and nearby areas. ${ }^{6}$ Later, Macnamara ${ }^{17}$ reported the isolation of ZIKV in one patient and the rise of antibody serum titles in two patients during an investigation of jaundice in Nigeria.

Sporadic cases of ZIKV infection had been reported in Africa and Asia until 2007, when an outbreak occurred in Yap State, Federated States of Micronesia. ${ }^{8,18}$ Lanciotti et al ${ }^{8}$ identified several cases of ZIKV infection by using serological and molecular analysis during this outbreak. Duffy et al ${ }^{18}$ investigated suspected cases of ZIKV presenting macular or papular rash, arthritis or arthralgia, and non-purulent conjunctivitis. From 185 suspected cases, 49 (26\%) cases were confirmed by positive reverse transcriptase polymerase chain reaction (RT-PCR) for ZIKV. In addition, 414 (74\%) of 557 investigated subjects had IgM anti-ZIKV in blood samples, but only 156 of those reported clinical symptomatic illness. ${ }^{18}$

More recently, in October 2013, a "mild dengue-like illness" was described in French Polynesia. ${ }^{19,20}$ Approximately 19,000 suspected cases were estimated, but ZIKV infection was confirmed in only 294 (49.5\%) of 584 patients submitted to serological tests. ${ }^{19}$ Subsequently, the virus spread to other countries, and several cases were described throughout the world, including Japan, Australia, Europe, and Latin America. ${ }^{12,21}$

The first autochthonous cases in Brazil were published in June 2015 that referred to patients who acquired the infection by March 2015. ${ }^{10}$ These patients exhibited fever, rash, conjunctivitis, and arthralgia with negative molecular and serological examinations for dengue and chikungunya viruses. ZIKV infection was confirmed by RT-PCR. ${ }^{10}$ A case of ZIKV infection acquired in March 2015 by an Italian traveler returning from Brazil was also reported in June 2015.22 In the first semester of 2015, health services in two states of the northeast of Brazil (Pernambuco and Bahia) reported a significant rise in the frequency of patients with mild fever, maculopapular rashes, headaches, non-purulent conjunctivitis, arthralgia, and myalgia. Serological tests for dengue and chikungunya viruses were negative, and ZIKV was detected by RT-PCR. ${ }^{11,23}$ Another outbreak was described in the southeast region, in Rio de Janeiro, with the identification of 364 suspected cases. ${ }^{24}$ Among 262 cases tested for ZIKV infection, 119 (71.9\%) had ZIKV RNA in serum collected during the acute phase of the disease. ${ }^{24}$ Subsequently, the Brazilian Ministry of Health reported that autochthonous transmission of ZIKV occurred in 18 states of the country from April to November 2015. ${ }^{25}$

In April 2016, a total of 91,387 cases of ZIKV infection had been reported in all Brazilian states, with an incidence of 44.7/100,000 inhabitants. ${ }^{26}$ Simultaneous infections of ZIKV and dengue virus were also described. ${ }^{27}$

From Brazil, ZIKV spread to other Latin American countries due to the large availability of the vector $A$. aegypti. Even in temperate regions with limited presence of the vector, there is great concern with possible autochthonous cases, especially through sexual transmission. ${ }^{28,29}$

\section{Infection during pregnancy and vertical transmission of ZIKV}

The first evidence of perinatal transmission of ZIKV was confirmed in two cases during the largest outbreak in French Polynesia. ${ }^{30}$ Both mothers presented cutaneous rash after delivery. One of the newborns presented a transient skin rash occurring 3 hours after phototherapy. Both mothers and newborns were serum positive by RT-PCR, and vertical transmission possibly occurred by transplacental route or during delivery. ${ }^{30}$

In October 2015, the Brazilian Ministry of Health issued an official communicate stating that 26 cases of neonatal microcephaly were notified from public and private services in Pernambuco state. ${ }^{31}$

Microcephaly is a neurological syndrome that can be associated with other malformations and is closely related to the development of the central nervous system (CNS). ${ }^{32}$ Its definition and clinical relevance vary among authors. ${ }^{33-35}$ For 
instance, cutoff points of head circumference measures $\leq 2$ or 3 standard deviation (SD) (from the mean expected values for age and sex) have been adopted. Children with head circumference $\leq 3 \mathrm{SD}$ are considered as having severe microcephaly, and they are more likely to have other structural abnormalities, more severe developmental impairment, and cognitive and behavioral problems than those with milder microcephaly. ${ }^{34,35}$

Until November 17, 2015, 399 suspected cases of microcephaly were identified in seven states of the northeast of Brazil. The majority of cases were concentrated in Pernambuco. From that moment onward, the Brazilian Ministry of Health recommended that all cases of microcephaly should be immediately reported. ${ }^{36}$ This event was reported to the World Health Organization (WHO) and classified as a potential public health emergency. ${ }^{37}$

It is worth mentioning that, until December 2015, the official parameter adopted for microcephaly definition in Brazil considered the cephalic perimeter $<33 \mathrm{~cm}$ for term newborns. ${ }^{38}$ From that point until March 2016, the parameter adopted for microcephaly notification was changed to a cephalic perimeter $<32 \mathrm{~cm}$ for term newborns of both sexes. ${ }^{38}$ This criterion change was proposed to increase the specificity of the test. ${ }^{39}$

In parallel to those official reports, confirmed cases of ZIKV infection in fetus and newborns have been published. ${ }^{40-42}$ The first reports identified virus genome in the amniotic fluid of two pregnant women whose fetuses had microcephaly, ${ }^{41,42}$ and in samples collected from a deceased neonate with $19 \mathrm{~cm}$ head circumference and severe hydrops who died just after birth. ${ }^{40}$ Calvet et $\mathrm{al}^{41}$ and Oliveira Melo et $\mathrm{al}^{42}$ described two cases in which amniotic fluid was collected from two pregnant Brazilian women who developed symptoms compatible with ZIKV infection at 10 and 18 weeks of gestation and whose fetuses had microcephaly. Ultrasound (US)-guided transabdominal amniocentesis was performed at 28 weeks of gestation, and ZIKV genome was identified in the amniotic fluid of both pregnant women, but not in their urine or serum. Fetal US at 25-27 weeks of gestation revealed severe CNS abnormalities, including microcephaly, asymmetric hemispheres, ventriculomegaly, hypoplastic cerebellum, and hypoplasia/ absence of the cerebellar vermis. Calcification areas were seen in later examinations. One infant was born at 40 weeks of gestation with a head circumference of $30 \mathrm{~cm}$, while the other newborn presented severe ventriculomegaly, microphthalmia, cataract, and severe arthrogryposis in legs and arms. ${ }^{41,42}$
Due to the temporal coincidence of these events, a possible association of microcephaly and ZIKV infection was hypothesized by the Brazilian Ministry of Health. ${ }^{40,43}$ Since then, a special task force was established to investigate the association between microcephaly and ZIKV infection during pregnancy. Notification of all cases of microcephaly became mandatory and in any case of pregnant women with suspected ZIKV infection pregnancy outcome must be monitored.

On December 1, 2015, given the increase in congenital abnormalities, GBS, and other neurological manifestations possibly related to ZIKV, the WHO released an epidemiologic alert with recommendations, including surveillance, case definition, diagnosis, vector control, and prevention measures for public health proceedings. ${ }^{37}$ On January 22, 2016, a report including the participation of the Brazilian Medical Genetics Society-Zika Embryopathy Task Force was posted in the Centers for Disease Control and Prevention (CDC) Morbidity and Mortality Weekly Report. ${ }^{44}$ In this report, Schuler-Faccini et $\mathrm{al}^{44}$ described 35 infants with microcephaly that had been born from August to October 2015 in eight among 26 states of Brazil. Four (11\%) infants had low birth weight, while arthrogryposis, talipes, microphthalmia abnormalities in fundoscopic examination were also reported. All mothers had lived in and/or visited ZIKV-affected areas during pregnancy, and $74 \%$ presented a skin rash during the first $(n=21)$ or second $(n=5)$ trimesters of pregnancy. Tests for other congenital infections were negative. Results of cerebrospinal fluid analysis were not available. Computed tomography (CT) scans and transfontanellar cranial USs identified brain calcifications (periventricular, parenchymal, thalamic, and in the basal ganglia areas), lissencephaly, pachygyria, and ventricular enlargement. ${ }^{44}$

Other studies reported ZIKV infection during pregnancy with confirmation of the virus by RT-PCR in both mother and fetus samples. On February 10, 2016, in Slovenia, Mlakar et $\mathrm{al}^{45}$ described a 25 -year-old woman who previously lived in the northeast of Brazil and exhibited, during the 13th week of gestation, a generalized maculopapular rash, high fever, severe musculoskeletal, and retro-ocular pain and itching, parallel to ZIKV epidemic in that community. The ultrasonography, at 29 weeks of gestation, identified intrauterine growth retardation (fetal weight at third percentile), microcephaly, moderate ventriculomegaly, and numerous calcifications in the placenta. Pregnancy was terminated at 32 weeks and fetal autopsy confirmed microcephaly, almost complete agyria, hydrocephalus, and multifocal dystrophic calcifications in the cortex and in the subcortical white matter. ${ }^{45}$ Simultaneously, another two cases 
of fetal loses and two cases of early neonatal deaths were described by Martines et al. ${ }^{46}$ All four mothers presented rash during the first trimester of pregnancy, but they were not tested for ZIKV. The two newborns died within 20 hours of life, and the histopathologic evaluation of brain showed parenchymal calcification, microglial nodules, gliosis, cell degeneration, and necrosis. Brain tissues were positive for ZIKV in RT-PCR. Tissues of the two miscarriages were also positive for ZIKV in RT-PCR. Immunohistochemistry also detected ZIKV antigen in tissues of two among four cases. Investigation for all other infectious agents related to vertical transmission was negative. ${ }^{46}$ On February 25, 2016, Sarno et $\mathrm{al}^{47}$ reported a case of fetal death at 32 weeks of pregnancy, without a clear previous history of ZIKV infection. Obstetric ultrasonography showed microcephaly, hydranencephaly, intracranial calcifications, and destructive lesions of posterior fossa. Pregnancy interruption occurred at the 32nd week, and RT-PCR was positive for ZIKV in cerebral, cortex, and medulla, and in amniotic fluid. ${ }^{47}$ In March 2016, Driggers et $\mathrm{l}^{48}$ published a case of a 33-year-old North American woman who had been in Mexico, Guatemala, and Belize with her husband on holidays. This woman developed fever, myalgia, ocular pain, and a skin rash in her eleventh week of gestation. Serologic analyses were positive for IgG antibodies and negative for IgM antibodies against dengue virus, and positive for both IgG and IgM antibodies against ZIKV, and the virus was also detected by RT-PCR assay at 16 and 21 weeks of gestation. Diffuse atrophy of the cerebral mantle, especially in the frontal and parietal lobes, and of "corpus callosum" was identified at the 20 th week by magnetic resonance imaging (MRI), and fetal head circumference decreased in sequential US images from the 47 th to 24 th percentile between 16 and 20 weeks of gestation. On postmortem analysis, the highest viral loads were found in fetal brain, but ZIKV was also identified in placenta, umbilical cord, and other fetal tissues, including muscle, liver, lung, and spleen. ${ }^{48}$ In March 2016, the CDC also published a retrospective analysis of cases from the period of August 2015 to February $2016 .{ }^{49}$ A total of 257 women were evaluated and $97 \%$ tested negative for recent ZIKV infection. Among the nine cases with confirmed ZIKV infection (RT-PCR, immunohistochemistry, and/or serologic tests in amniotic fluid, placenta, or serum), six pregnant women reported symptoms during the first trimester: two early pregnancy losses occurred, two pregnancies were electively terminated, one infant with microcephaly was born alive, and one pregnancy was still continuing when the article was published. In three women whose symptoms occurred during the second and third trimesters, no abnormalities were identified in the newborns. ${ }^{49}$

A cohort study from Rio de Janeiro/Brazil enrolled 88 pregnant women (from 5 to 38 weeks of gestation) who had started with cutaneous rash within the 5 days prior the study recruitment. ${ }^{46} \mathrm{ZIKV}$ infection was identified by realtime RT-PCR in $72(82 \%)$ of them in blood and/or urine samples. US was performed in 42 women with positive ZIKV infection, and fetal abnormalities (in utero growth restriction with or without microcephaly, ventricular calcifications, abnormal amniotic fluid volume, or altered cerebral or umbilical artery flow) were detected in $29 \%$ of them. Two fetal deaths occurred at 36 and 38 weeks of gestation. ${ }^{50}$

In April 2016, three studies described image changes in Brazilian cases of microcephaly. ${ }^{51-53}$ A study from Recife, the capital of the state of Pernambuco/Brazil, evaluated 23 infants with congenital microcephaly and epidemiology suggestive of congenital ZIKV infection. ${ }^{51} \mathrm{ZIKV}$ IgM antibodies were detected in the cerebrospinal fluid of seven infants. Other infections were excluded by serological analysis. Brain CT showed intracranial calcifications in all cases, mainly in frontal and parietal lobes and at the corticomedullary junction, basal ganglia, and thalamus. Ventriculomegaly (severe in $53 \%$ ) and global hypogyration of the cerebral cortex were also found in all infants. Cerebellar hypoplasia and abnormal hypodensity of the white matter were also described. ${ }^{51}$ In another study from Pernambuco, neuroradiological examinations of children with a diagnosis of microcephaly, who were born during the ZIKV outbreak in 2015/2016, were retrospectively evaluated. ${ }^{52}$ After the exclusion of other known causes of microcephaly, the final sample with suspect ZIKV infection comprised 23 infants. In six cases, cerebrospinal fluid was analyzed and IgM antibodies against ZIKV were positive. In the remaining 17 infants, the diagnosis was suspected, but without laboratory confirmation. Descriptions of the radiological abnormalities identified in CTs included decreased brain volume, ventriculomegaly, and cerebral calcifications (in cortical and subcortical junctions, basal ganglia, and periventricular areas). Simplified gyral pattern, hypogenesis/hypoplasia of corpus callosum, and delayed myelination were also described in MRI examinations. ${ }^{52}$ Cavalheiro et al ${ }^{53}$ evaluated 13 term newborns with microcephaly, whose mothers presented cutaneous rash within the first 4 months of pregnancy. Other infectious agents were excluded. In all of them, decreased cerebral mantle, increased subarachnoid space and ventriculomegaly, lissencephaly, and hypoplasia of the corpus callosum were observed in 
brain CT and/or MRI. Only one case exhibited periventricular calcifications, whereas, in others, calcifications were mostly localized in the subcortical/cortical transition area and in the basal ganglia. ${ }^{53}$ In May 2016, another case report from Rio de Janeiro described a 27-year-old woman, within the 12th week of gestation exhibiting symptoms of fever, maculopapular rash, and arthralgia. ${ }^{54}$ Serology testing for congenital infections and dengue and chikungunya virus was negative. Normal fetal anatomy was seen in US examinations at 12 and 21 weeks of gestation, but microcephaly was suspected at the 32-week scan. Microcephaly was confirmed at the 37-week scan along with diffuse brain calcifications. Fetal MRI additionally revealed reduced gyration and asymmetric colpocephaly. Neonatal head circumference was $29.0 \mathrm{~cm}$, and transfontanellar US examination identified subcortical and periventricular calcifications with ventricular dilatation. Postnatal CT also revealed brain calcifications, cortical atrophy, small anterior fontanel, and premature closure of coronal and metopic sutures. ${ }^{54} \mathrm{Up}$ to May 7, 2016, the Brazilian Ministry of Health reported 7,438 suspected cases of microcephaly, among which 2,679 cases were excluded and 3,433 were still under investigation. A total of 1,326 cases of microcephaly were confirmed, but only 205 of them had laboratorial confirmation of ZIKV infection. ${ }^{55}$

Studies also retrospectively evaluated the frequency of fetal abnormalities possibly due to ZIKV outbreak in French Polynesia that affected $\sim 66 \%$ of the population. ${ }^{56,57}$ In the 23-month period included in the study, eight cases of microcephaly were identified, of which five resulted in termination of pregnancy by medical abortion. ${ }^{56}$ This study estimated the risk of microcephaly after ZIKV infection in pregnancy in $0.95 \%$, and the first trimester seems to be the period at highest risk. ${ }^{56}$ It is worth mentioning that, based on the analysis of Brazilian data, Johansson et $\mathrm{al}^{57}$ proposed the risk of microcephaly ranging from $0.88 \%$ to $13.2 \%$ of ZIKV infection occurring in the first trimester of pregnancy, depending on the overall infection rate estimates. The lower end of this range was similar to the $\sim 1 \%$ risk estimated for French Polynesia. Still there, a retrospective evaluation of 19 cases of congenital cerebral malformations, including five cases of microcephaly, described positive identification of ZIKV RNA by RT-PCR in four of them. ${ }^{58}$ Another study reviewed the occurrence of fetal abnormalities in 4,285 births in the Polynesia Hospital Center. ${ }^{59}$ Twelve cases of malformations were identified, and among them three cases of fetuses with severe CNS abnormalities and positive PCR for ZIKV in the amniotic fluid. Calcifications and ventriculomegaly were observed in all cases in fetal US.
Microcephaly, low cerebellar biometry, occipital subependymal pseudocysts, polymicrogyria with laminar necrosis and opercular dysplasia, absent/or hypoplastic corpus callosum, and hypoplastic brainstem were detected through MRI. ${ }^{59}$

The studies describing radiological abnormalities of the CNS in fetuses and neonates with presumed congenital ZIKV infection are summarized in Table 1.

Ocular abnormalities in neonates possibly associated with ZIKV infection have also been reported. In a sample of 29 infants, from Salvador, Bahia, Brazil, with microcephaly and a presumed diagnosis of congenital ZIKV infection, ocular abnormalities were found in ten children (34.5\%), and, in seven, the alterations were bilateral. The authors described focal pigment mottling of the retina and chorioretinal atrophy, optic nerve abnormalities, bilateral iris coloboma, and lens subluxation. From this sample, 23 mothers reported symptoms compatible with ZIKV infection during pregnancy, of which 18 occurred in the first trimester, four in the second trimester, and one in the third trimester. ${ }^{60}$ A study from Recife, Pernambuco, Brazil, showed ten infants with similar ocular abnormalities, including gross pigment mottling and/or chorioretinal atrophy and optic nerve abnormalities. Seven mothers (70\%) referred symptoms during pregnancy, six of them in the first trimester. ${ }^{61}$ Unfortunately, the diagnosis of ZIKV infection was based on the clinical symptoms of the mother during pregnancy, and also the exclusion of other infections such as syphilis, HIV, toxoplasmosis, cytomegalovirus, herpes simplex virus, and rubella.

\section{Controversies on causal association between ZIKV infection and microcephaly}

The absence of a unified definition of microcephaly has had important epidemiological consequences. Since March 2016, the official criteria used to diagnose microcephaly in Brazil have been based on the WHO recommendations: ${ }^{61,62}$ 1) for term babies, international parameters of the WHO should be used and 2) for preterm newborns, the intergrowth parameters should be used. Initially, the definition of cases of microcephaly in the surveillance system included all fullterm infants with a head circumference $\leq 33 \mathrm{~cm}$, and later the inclusion criteria were modified to $\leq 32 \mathrm{~cm} .{ }^{63}$ However, the National Live Birth Information System adopted a definition of microcephaly when head circumference measure was $\leq 3 \mathrm{SD}$ from the mean expected for age and sex. ${ }^{64,65}$ Therefore, variations in the number of suspected cases may have occurred according to the definitions adopted and may have resulted in lower diagnostic specificity, leading to possible overestimation 


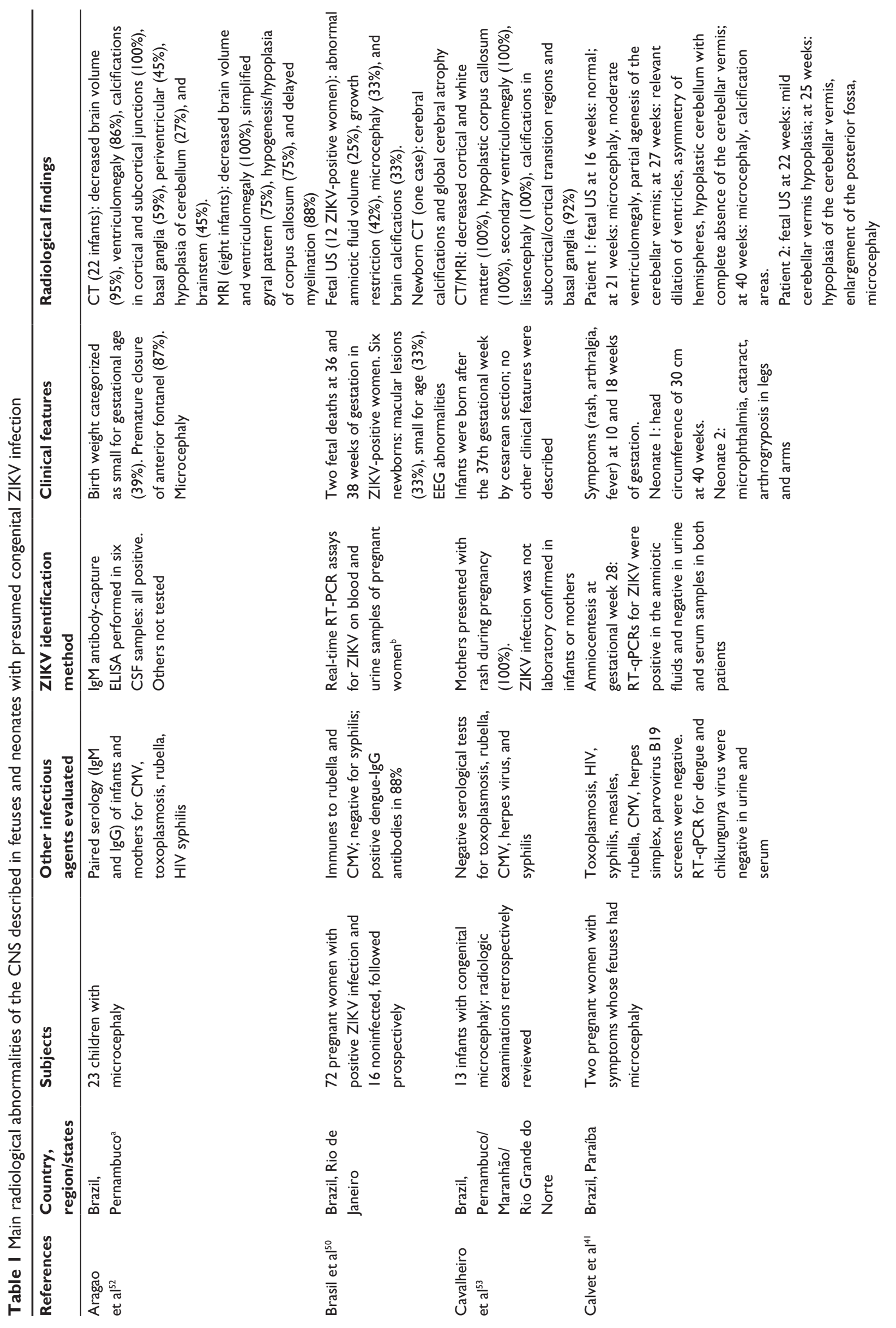




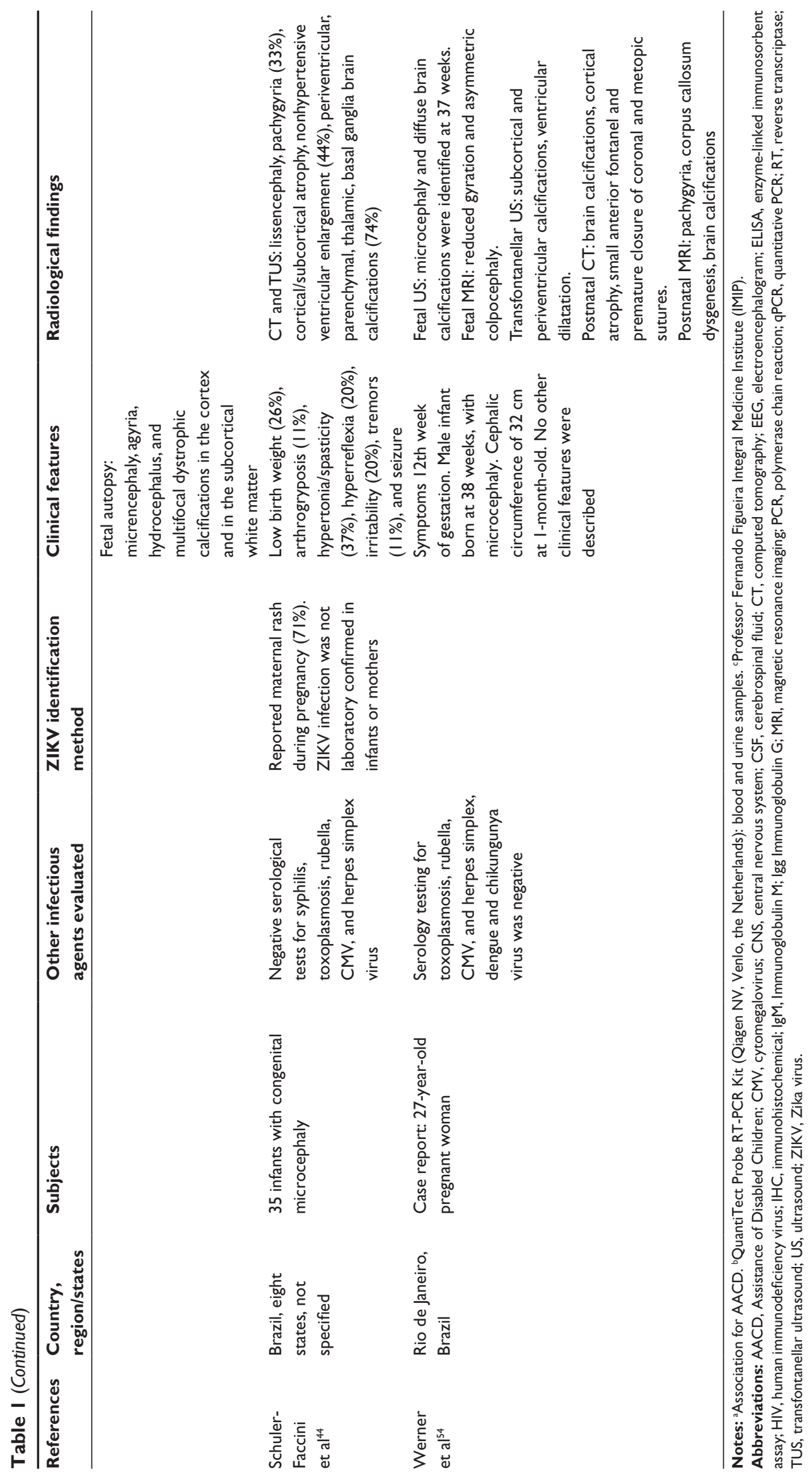


of affected infants. ${ }^{39,65}$ Furthermore, the real incidence of microcephaly in Brazil, prior to the occurrence of ZIKV infectious, was possibly underestimated, especially in the northeast region, and the obligatory notification of cases may falsely inflate the real incidence. ${ }^{39,66,67}$ In a communicate, the Latin American Collaborative Study of Congenital Malformations (ECLAMC 2015) questioned the number of reported cases, stating that they were much higher than the expected considering the incidence of ZIKV infection in the Brazilian population. ${ }^{68}$

Other possible etiologies of microcephaly including environmental, alcohol-related, infectious or genetic, and/or associated factors (malnutrition, coinfection with other agents) also must be more carefully investigated. ${ }^{66}$ Congenital microcephaly is clearly associated with genetic and acquired conditions (for review, refer Nunes et $\mathrm{al}^{69}$ ). Exposure to drugs, including alcohol, maternal infection, and nutritional deficiency is the major cause of acquired congenital microcephaly. Regardless of the cause, the etiopathogenic factor must influence the proliferation phase of the CNS development, around third and fourth months of pregnancy, to determine microcephaly. Accordingly, ZIKV infection could cause microcephaly only when occurring in the first months of pregnancy. In this regard, convincing epidemiological data are missing. ${ }^{70}$ Although this relationship still needs further clarification, some of the evidence described so far suggests the possibility of ZIKV-related teratogenic effects. ${ }^{44,71,72}$ In terms of public health safety measures, while prospective studies are not finalized and/or more robust evidence is available, precautions to control vector multiplication and to reduce individual exposure to the virus, especially in fertile and pregnant women, are recommended throughout the world..$^{31,37,73}$ The continuous surveillance of suspected cases is also maintained, and a recent report from the $\mathrm{WHO}^{74}$ enlists eight countries that have reported cases of microcephaly and/or CNS malformations that were potentially associated with ZIKV infection: Brazil, Cape Verde, Colombia, French Polynesia, Martinique, Panama, Slovenia, and the USA. In the last two countries, the probable place of infection was located in South/Central America.

Table 2 depicts arguments for and against a causal association between ZIKV infection and microcephaly.

\section{Neuronal damage by ZIKV: evidence from experimental models and unanswered questions}

ZIKV infection has been linked to severe neurological complications, that is, microcephaly and GBS. While the first condition involves the CNS and the second is related to peripheral nerves lesion. The mechanisms by which ZIKV can determine these two distinct syndromes are still uncertain. The virus could directly affect CNS and peripheral neurons. Alternatively, neuronal lesion could result from ZIKV-elicited processes, including immune response and loss of glial support. So far, studies have focused on the first hypothesis implicating a direct effect of ZIKV on neurons.

Although suggestive, the detection of ZIKV in the brain of microcephalic human fetus ${ }^{45}$ does not prove either causality or pathogenic mechanism. To overcome the limitations of human studies, in vitro and in vivo experimental approaches have been pursued.

Two independent studies showed that ZIKV can infect neural stem cells in vitro, inducing caspase-mediated cell death. ${ }^{75,76}$ The most compelling evidence for a direct role played by ZIKV in microcephaly came from an elegant study using induced pluripotent stem cells cultured as neurospheres and brain organoids, in in vitro models of embryonic brain development. Garcez et $\mathrm{al}^{76}$ showed that ZIKV reduced the viability and growth of neural stem cells in these models, disrupting the formation of both structures. To control for unspecific effects of viral infection on neurogenesis, the same experiments were performed with dengue virus 2 , a flavivirus with genetic and serological similarities to ZIKV. Neurospheres and brain organoids exposed to dengue virus 2 did not have their growth and development altered, suggesting that neurogenesis impairment is not a general feature of the flavivirus family. ${ }^{76}$

Until recently, only a very limited number of studies had been performed in rodents, indicating that ZIKV can replicate and damage CNS cells. ${ }^{77,78}$ Among the concerns regarding these older studies, there is the use of the prototype MR 766 strain of ZIKV that had undergone multiple passages in suckling mouse brains, possibly changing its biological properties, including virulence. Alterations in molecular components of ZIKV overtime could also be responsible for its increased neuropathogenicity lately. To overcome these limitations, Lazear et $\mathrm{al}^{79}$ assessed four ZIKV strains (three strains isolated from mosquitoes in Africa and one contemporary clinical isolate) in wild-type (WT) C57BL/6 mice and immune-deficient transgenic mice. Four- to six-weekold WT mice inoculated with ZIKV by subcutaneous route did not develop any clinical sign of disease, while different strains of mice lacking interferon $\alpha / \beta$ (or type 1 ) signaling developed neurological signs (muscle weakness) and succumbed to the infection. Ifnar1-/-mice, which cannot respond to interferon $\alpha / \beta$, were highly vulnerable to the infection 
Table 2 Supporting and controversial evidence of the association between ZIKV infection during pregnancy and fetal abnormalities

\begin{tabular}{|c|c|}
\hline Supporting evidence & Controversial evidence \\
\hline \multicolumn{2}{|l|}{ Fetal involvement with maternal infection occurring during first trimester } \\
\hline \multicolumn{2}{|l|}{ or early second trimester } \\
\hline Presence of ZIKV antibodies in maternal serum ${ }^{45,48,49}$ & ZIKV infection inferred only by epidemiological/clinical criteria ${ }^{44,49,53,54,56}$ \\
\hline $\begin{array}{l}\text { Isolation of ZIKV during pregnancy (maternal serum/urine, amniotic } \\
\text { fluid) } 3,41,42,49,50,58\end{array}$ & Risk of infection after first trimester could not be excluded \\
\hline $\begin{array}{l}\text { Isolation of ZIKV antibodies in samples from fetus/neonates (fetal } \\
\text { necropsy, cerebrospinal fluid) }\end{array}$ & $\begin{array}{l}\text { Despite the fact that infection seems to cause more severe disease in } \\
\text { fetus during the first trimester, data regarding exposure and disease } \\
\text { cannot be totally explained }\end{array}$ \\
\hline \multicolumn{2}{|l|}{ Common phenotype in cases with isolation of ZIKV in fetus/neonates } \\
\hline Microcephaly ${ }^{41,42,47,48,51,52,58}$ & Mild phenotypes could also be associated with ZIKV infection, since \\
\hline Fetal death ${ }^{40,47,49,50}$ & only severe cases have been reported \\
\hline \multicolumn{2}{|l|}{ Intracranial calcifications ${ }^{47,51-53}$} \\
\hline \multicolumn{2}{|l|}{ Cerebral atrophy ${ }^{45,48,52}$} \\
\hline \multicolumn{2}{|l|}{ Destructive lesions ${ }^{47}$} \\
\hline \multicolumn{2}{|l|}{ Anomalies of cortical development/gyration ${ }^{51-53}$} \\
\hline \multicolumn{2}{|l|}{ Common phenotype in cases with presumed infection } \\
\hline \multicolumn{2}{|l|}{ Ocular lesions 60,61} \\
\hline \multicolumn{2}{|l|}{$\begin{array}{l}\text { Reports of fetuses and infants with microcephaly who are born to women } \\
\text { who travel to countries with active ZIKV transmission }\end{array}$} \\
\hline \multicolumn{2}{|l|}{ In Slovenia, a pregnant woman who was living in the northeast of Brazil } \\
\hline \multicolumn{2}{|l|}{ during ZIKV outbreak. ${ }^{45} \mathrm{~A}$ pregnant woman who had been to Mexico, } \\
\hline \multicolumn{2}{|l|}{ Guatemala, and Belize on holiday ${ }^{48}$} \\
\hline \multirow{2}{*}{\multicolumn{2}{|c|}{$\begin{array}{l}\text { Six pregnant women who had traveled to areas with active } \\
\text { transmission of } \text { ZIKV }^{49}\end{array}$}} \\
\hline & \\
\hline \multirow{5}{*}{$\begin{array}{l}\text { Virus presence in fetal and neonatal samples, and similar findings are } \\
\text { presented in other congenital infections } \\
\text { The findings of microcephaly, premature fetal death, intracranial } \\
\text { calcifications, and CNS abnormalities are similar to the effects of other } \\
\text { known congenital infectious agents and environmental toxins }{ }^{69}\end{array}$} & The evaluation of placental tissues, fetal death and neonatal death are \\
\hline & necessary to determine the effect of gestational age during maternal \\
\hline & illness on fetal outcomes. \\
\hline & Experimental evidence of infection of neural stem cells in in vitro ${ }^{75,76}$ \\
\hline & and animal models ${ }^{76,77}$ \\
\hline \multirow{2}{*}{$\begin{array}{l}\text { Strong temporal and geographical association of ZIKV and neurological } \\
\text { involvement }\end{array}$} & Due to changes in microcephaly definition, obligatory notification, and \\
\hline & absence of confirmation of etiology in several cases, an overestimation \\
\hline Brazil & of ZIKV-affected infants should be considered in Brazil. ${ }^{39,65-67}$ Other \\
\hline Brazilian Ministry of Health ${ }^{36,55}$ & etiologies of microcephaly should also be ruled out. ${ }^{69}$ \\
\hline \multirow{8}{*}{$\begin{array}{l}\text { Northeast }{ }^{51,52} \\
\text { Southeast }{ }^{54} \\
\text { French Polynesian } \\
\text { Retrospective studies } \\
\text { S6,58,59 }\end{array}$} & Ideally, consistent findings should be performed by two or more high- \\
\hline & quality epidemiologic studies, with the control of confounding factors, \\
\hline & sufficient numbers, exclusion of positive and negative bias factors, \\
\hline & prospective studies if possible, and relative risk higher than 6.0 . \\
\hline & However, literature until now includes only surveys and retrospective \\
\hline & or short-term cohort studies. Therefore, until a large epidemiological \\
\hline & study is published, it is not possible to confirm the association \\
\hline & between maternal exposure and fetal involvement \\
\hline
\end{tabular}

Abbreviations: CNS, central nervous system; ZIKV, Zika virus.

and exhibited high levels of ZIKV in all tissues evaluated, including blood, spleen, testes, brain, and spinal cord. Interestingly, ZIKV could cause disease in non-weaned WT mice, that is, 1-week-old, when the innate immune response is not yet mature, indicating an age-dependent vulnerability to disease. ${ }^{79}$ Besides proposing a model for therapeutic and pathogenesis investigation, this study confirmed a pivotal role played by interferon $\alpha / \beta$ in restricting ZIKV infection, as already described for dengue virus infection.

Rossi et $\mathrm{al}^{80}$ also suggested a significant role played by type I interferon in the resistance against ZIKV infection.
Using a Cambodian isolate inoculated by intraperitoneal route, they found that 3 -week-old 129 sv mice lacking the interferon $\alpha / \beta$ receptor (A129) succumbed to the infection, while immunocompetent mice survived. An age-dependent vulnerability to disease was also demonstrated in this model with 3-week-old mice exhibiting more severe signs of infection than 5- and 11-week-old mice. ZIKV was detected in the brain on day 3 postinfection and caused neurological signs (lethargy, tremor) by day 5 postinfection, especially in 3-week-old A129. ${ }^{80}$ Mice lacking both interferon $\alpha / \beta$ and $\gamma$ (or type II) receptors (AG129) infected by intraperitoneal 
or intradermal routes also developed a severe disease, dying on day 6 postinfection. Given the antiviral activity of interferons, these results were not surprising, being also corroborated by an in vitro study showing the potential of interferons $\alpha / \beta$ and $\gamma$ in controlling ZIKV replication. ${ }^{81}$ The major limitation of the models proposed so far pertains to the fact that susceptible animals lack a key component of the innate immune response against viral infection. This certainly influences how the immune system deals with the ZIKV infection, affecting the evaluation of the real role played by immune mechanisms on disease pathogenesis. In fact, mechanistic insights are still missing in in vivo studies, particularly those related to neuronal damage. In addition, it is uncertain whether ZIKV promotes widespread or localized brain damage, and careful neuropathological analysis coupled with behavioral assessment is warranted in these and future animal models of ZIKV. The age-dependent vulnerability to disease must be further explored, including intrauterine infection at different stages of fetus development. This latter issue is of paramount importance taking into consideration the controversies regarding the association between prenatal ZIKV infection and microcephaly. More importantly, it is uncertain the consequences of ZIKV infection after this critical period on CNS development. Theoretically, neuronal migration, organization, and myelination could be impaired by CNS infection, leading to different conditions, including major (eg, lissencephaly and schizencephaly) and minor (eg, focal dysplasias) brain malformations, and "functional" neuropsychiatric syndromes including intellectual impairment and autism. Longitudinal cohorts of newborns from epidemic areas, involving systematic assessment of neurodevelopmental milestones, can help answering this issue.

\section{GBS and other autoimmune- mediated disorders}

The first link between ZIKV infection and a neurological complication occurred in the ZIKV outbreak in French Polynesia from October 2013 to March $2014 .^{82}$ Cao-Lormeau et al ${ }^{83}$ reported 42 patients with GBS during this ZIKV outbreak, corresponding approximately to a 20 -fold increase in the expected number of cases of GBS for that region. GBS is an acute autoimmune peripheral polyneuropathy characterized by the development of ascending motor weakness associated with variable degrees of cranial nerves palsy, sensory changes, and dysautonomia. ${ }^{84}$ The disease is self-limiting, reaching its nadir after 2-4 weeks of onset. Depending on its severity, it can affect respiratory muscles, requiring artificial ventilation support.
In the reported cases, most patients (88\%) had a previous history of a short-lasting viral syndrome characterized by fever, rash, arthralgia, and/or conjunctivitis, and all were positive for ZIKV serological tests. The GBS in these patients differed from the typical syndrome as it was marked by a fast progression to a nadir ( $<1$ week) and a short plateau phase. Facial palsy was a common manifestation (64\%), and onethird of patients required respiratory assistance. Besides the combination of fast onset and fast recovery, patients lacked the typical demyelinating pattern of the disease, exhibiting the acute motor axonal neuropathy (AMAN) type. ${ }^{83}$ In contrast with non-ZIKV-related AMAN cases, the patients did not show the characteristic anti-ganglioside antibodies. The atypical presentation along the lack of AMAN-related antibodies cast doubt on the anti-glycolipid antibody role on disease pathogenesis. ${ }^{83,85}$ In this scenario, a direct effect of ZIKV can be implicated again. All patients in Cao-Lormeau et al's ${ }^{83}$ series were treated with intravenous immunoglobulin, one of the standard treatments for GBS along with plasmapheresis. ${ }^{84}$ It remains to be defined whether the favorable clinical outcome observed in this study could be achieved with plasmapheresis and/or lack of specific treatment. The latter may happen in regions with limited economic and health resources.

As with obstetric complications, including microcephaly, there are several challenges ahead. First, the epidemiological data must be confirmed. Preliminary reports from different Latin American countries seem to corroborate the association between ZIKV and GBS. ${ }^{86}$ This also undermines an eventual role played by ethnic-related factors, such as Human Leukocyte Antigen alleles, in post-ZIKV GBS. ${ }^{78}$ However, direct and/or indirect pathogenic roles for ZIKV must be proved. In this regard, animal models may be helpful, but so far no study has evaluated peripheral nerves lesion or dysfunction following ZIKV. It is also tempting to speculate whether ZIKV can be implicated in other autoimmune neurological diseases, as occurred with dengue virus. ${ }^{87}$ Mécharles et al ${ }^{88}$ reported a case of acute myelitis possibly due to ZIKV infection. In 2016, at the American Academy of Neurology Meeting, Doctor Ferreira ${ }^{89}$ reported two Brazilian patients with acute disseminated encephalomyelitis and ZIKV infection, calling great attention to this issue. To prevent unnecessary alarm, sporadic reports must be confirmed by careful epidemiological analysis, especially taking into consideration the concurrent circulation of other arboviruses, such as dengue. To date, there is no evidence of an increased rate of acute disseminated encephalomyelitis or related autoimmune conditions in regions facing ZIKV outbreak. 
Table 3 Unanswered questions regarding ZIKV infection and neuropsychiatric complications

What are the mechanisms underlying ZIKV-induced neuronal damage? What is the role of the immune response against ZIKV in the pathogenesis of neurological complications?

What are the risk and protective factors related to the development of neurological complications after ZIKV infection?

Are there differences in ZIKV infection during the first trimester of pregnancy according to maternal immune response and/or viral load? Is there any neurological and/or psychiatric consequence for the fetus of ZIKV infection in the second half of pregnancy?

Is the ZIKV infection associated with other immune-mediated neurological diseases?

Abbreviation: ZIKV, Zika virus.

\section{Conclusion}

There is a clear temporal association between the increased reporting of cases of microcephaly and of GBS and the ZIKV outbreak. However, there are several unanswered questions that must be investigated (Table 3). For instance, studies addressing the mechanisms underlying ZIKV-induced neuronal damage are warranted. Reliable diagnostic criteria for the identification of cases of microcephaly are still required. In addition, ongoing longitudinal cohort studies can show the long-term neurological and psychiatric consequences of congenital and after-birth ZIKV infection. From a personal perspective, as neither pharmacological treatment nor vaccines are available, prevention of ZIKV infection relies on protective measures against mosquito bites.

Further studies on ZIKV infection are urgently needed and may help the development of therapeutic strategies against ZIKV and other arboviruses, such as dengue and chikungunya.

\section{Acknowledgment}

This study was partially supported by FAPEMIG (Fundação de Amparo à Pesquisa do Estado de Minas Gerais, Brazil).

\section{Disclosure}

The authors report no conflicts of interest in this work.

\section{References}

1. Kuno G, Chang GJ. Full-length sequencing and genomic characterization of Bagaza, Kedougou, and Zika viruses. Arch Virol. 2007; 152(4):687-696.

2. Faye $\mathrm{O}$, Freire CCM, Iamarino A, et al. Molecular evolution of Zika virus during its emergence in the 20th century. PLoS Negl Trop Dis. 2014; 8(1):e2636.

3. Weaver SC, Costa F, Garcia-Bianco MA, et al. Zika virus: history, emergence, biology, and prospects to control. Antiviral Res. 2016;130: 69-80.
4. Haddow AJ, Smithburn KC, Dick GWA, Kitchen SF, Lumden WHR. Implication of the mosquito Aedes (Stegomyia) africanus Theobald in the forest cycle of yellow fever in Uganda. Ann Trop Med Parasit. $1948 ; 42: 218-223$.

5. Dick GW, Kitchen SF, Haddow AJ. Zika virus I. Isolations and serological specificity. Trans R Soc Trop Med Hyg. 1952;46(5):509-520.

6. Dick GW. Zika virus. II. Pathogenicity and physical properties. Trans R Soc Trop Med Hyg. 1952;46(5):521-534.

7. Haddow AJ, Willians JP, Simpson H, Goma LKH. Twelve isolations of Zika virus from Aedes (Stegomyia) africanus (Theobald) taken in and above a Uganda Forest. Bull World Heath Org. 1964;31:57-69.

8. Lanciotti RS, Kosoy OL, Laven JJ, et al. Genetic and serologic properties of Zika virus associated with an epidemic, Yap State, Micronesia, 2007. Emerg Infect Dis. 2008;14(8):1232-1239.

9. Lanciotti RS, Lambert AJ, Holodniy M, Saavedra S, del Carmen Castillo Signor L. Phylogeny of Zika virus in Western Hemisphere, 2015. Emerg Infect Dis. 2016;22(5):933-935.

10. Zanluca C, de Melo VC, Mosimann AL, dos Santos GI, dos Santos CN, Luz K. First report of autochthonous transmission of Zika virus in Brazil. Mem Inst Oswaldo Cruz. 2015;110(4):569-572.

11. Campos GS, Bandeira AC, Sardi SI. Zika virus outbreak, Bahia, Brazil. Emerg Infect Dis. 2015;21(10):1885-1886.

12. Musso D. Zika virus transmission from French Polynesia to Brazil. Emerg Infect Dis. 2015;21(10):1887-1888.

13. Giovanetti M, Faria NR, Nunes MR, et al. Zika virus complete genome form Salvador, Bahia, Brazil. Infect Genet Evol. 2016;41:142-145.

14. Faria NR, Azevedo RS, Kraemer MU, et al. Zika virus in the Americas: early epidemiological and genetic findings. Science. 2016;352(6283): 345-349.

15. Boorman JP, Poeterfield JS. A simple technique for infection of mosquitoes with viruses; transmission of Zika virus. Trans $R$ Soc Trop Med Hyg. 1956;50(3):238-242.

16. Simpson DI. Zika virus infection in man. Trans R Soc Trop Med Hyg. 1964;58:335-338.

17. Macnamara FN. Zika virus: a report on three cases of human infection during an epidemic of jaundice in Nigeria. Trans R Soc Trop Med Hyg. 1954;48(2):139-145.

18. Duffy MR, Chen TH, Hancock WT, et al. Zika virus outbreak on Yap Island, Federal States of Micronesia. N Engl J Med. 2009;360(24): $2536-2543$.

19. Cao-Lormeau VM, Roche C, Teissier A, et al. Zika virus, French Polynesia, South Pacific, 2013. Emerg Infect Dis. 2014;20(6):2924-2930.

20. Mallet H, Vial A, Musso D [webpage on the Internet]. Bulletin d'information sanitaires, épidémiologiques et statistiques. Bilan de l'épidémie à virus Zika en Polynésie Française 2013-2014; 2015. Available from: http://www.hygiene-publique.gov.pf/IMG/pdf/ no13_-_mai_2015_-_zika.pdf. Accessed January 14, 2016.

21. Paixão ES, Barreto F, da Glória Teixeira M, da Conceição N Costa M, Rodrigues LC. History, epidemiology, and clinical manifestations of Zika: a systematic review. Am J Public Health. 2016;106(4): 606-612.

22. Zammarchi L, Tappe D, Fortuna C, et al. Zika virus infection in a traveller returning to Europe from Brazil, March 2015. Euro Surveill. 2015;20(23):pii:21153.

23. Pessoa R, Patriota JV, Lourdes de Souza Md, Felix AC, Mamede N, Sanabani SS. Investigation into an outbreak of dengue-like illness in Pernambuco, Brazil, revealed a cocirculation of Zika, Chikungunya, and dengue virus type 1. Medicine (Baltimore). 2016;95(12):e3201.

24. Brasil P, Calvet GA, Siqueira AM, et al. Zika virus outbreak in Rio de Janeiro, Brazil: clinical characterization, epidemiological and virological aspects. PLoS Negl Trop Dis. 2016;10(4):e0004636.

25. Brazil 2015 [webpage on the Internet]. Boletim Epidemiológico Volume $46-\mathrm{n}^{\mathrm{o}} 35$ - 2015 - Monitoramento dos casos de dengue e febre de chikungunya até a Semana Epidemiológica 43, 2015. Available from: http://portalsaude.saude.gov.br/images/pdf/2015/novembro/26/2015dengue-SE45.pdf. Accessed April 29, 2016. 
26. Brazil 2016 [webpage on the Internet]. Ministério da Saúde Secretaria de Vigilância em Saúde - Boletim Epidemiológico Monitoramento dos casos de dengue, febre de chikungunya e febre pelo vírus Zika até a Semana Epidemiológica 13, 2016. Disponível em: http://portalsaude. saude.gov.br/images/pdf/2016/abril/27/2016-014---Dengue-SE13substitui----o.pdf. Accessed May 4, 2016.

27. Calvet GA, Filippis AM, Mendonça MC, et al. First detection of autochthonous Zika virus transmission in a HIV-infected patient in Rio de Janeiro, Brazil. J Clin Virol. 2016;74:1-3.

28. Venturi G, Zammarchi L, Fortuna C, et al. An autochthonous case of Zika due to possible sexual transmission, Florence, Italy, 2014. Euro Surveill. 2016;21(8).

29. Zammarchi L, Stella G, Mantella A, et al. Zika virus infections imported to Italy: clinical, immunological and virological findings, and public health implications. J Clin Virol. 2015;63:32-35.

30. Besnard M, Lastere S, Teissier A, Cao-Lormeau V, Musso D. Evidence of perinatal transmission of Zika virus, French Polynesia, December 2013 and February 2014. Euro Surveill. 2014;19(13):pii:20751.

31. Brazil 2015 [webpage on the Internet]. Boletim Epidemiológico Volume 46 - no 34 - 2015 - Situação epidemiológica de ocorrência de microcefalias no Brasil, 2015. Available from: http://portalsaude. saude.gov.br/images/pdf/2015/novembro/19/Microcefalia-bol-final. pdf. Accessed May 1, 2016.

32. Malinger G, Lev D, Lerman-Sagie T. Assessment of fetal intracranial pathologies first demonstrated late in pregnancy: cell proliferation disorders. Reprod Biol Endocrinol. 2003;1:110.

33. Abuelo D. Microcephaly syndromes. Semin Pediatr Neurol. 2007;14(3): 118-127.

34. Ashwal S, Michelson D, Plawner L, Dobyns WB; Quality Standards Subcommittee of the American Academy of Neurology and the Practice Committee of the Child Neurology Society. Practice parameter: evaluation of the child with microcephaly (an evidence-based review): report of the Quality Standards Subcommittee of the American Academy of Neurology and the Practice Committee of the Child Neurology Society. Neurology. 2009;73(11):887-897.

35. Stoler-Poria S, Lev D, Schweiger A, Lerman-Sagie T, Malinger G. Developmental outcome of isolated fetal microcephaly. Ultrasound Obstet Gynecol. 2010;36(2):154-158.

36. Brazil 2015 [webpage on the Internet]. Informe epidemiológico $\mathrm{n}^{\circ}$ 01/2015-Semana epidemiológica 46 (15 a 21/11/2015). Monitoramento dos casos de microcefalias no Brasil. Available from: http://portalsaude. saude.gov.br/images/pdf/2015/novembro/24/COES-Microcefalias---Informe-Epidemiol--gico---SE-46---24nov2015.pdf. Accessed May 1, 2016

37. Pan American Health Organization/World Health Organization (PAHO/ WHO) 1 December 2015 [webpage on the Internet]. Neurological syndrome, congenital malformations, and Zika virus infection. Implications for public health in the Americas - Epidemiological Alert. Available from: http://www.paho.org/hq/index.php?option=com_docman\&task=doc_v iew\&Itemid=270\&gid=32405\&lang=en. Accessed April 29, 2016.

38. Brazil 2016 [webpage on the Internet]. Informe epidemiológico $n^{\circ} 23$ - Semana epidemiológica (se) 16/2016 (17/04 a 23/04/2016). Monitoramento dos casos de microcefalias no Brasil. Available from: http://portalsaude.saude.gov.br/images/pdf/2016/abril/27/ COES-Microcefalias---Informe-Epidemiol--gico-23--SE-16-2016-25abril2016-20h07.pdf. Accessed May 2, 2016.

39. Victora CG, Schuler-Faccini L, Matijasevich A, Ribeiro E, Pessoa A, Barros FC. Microcephaly in Brazil: how to interpret reported numbers? Lancet. 2016;387(10019):621-624.

40. Brazil 2015 [webpage on the Internet]. Boletim Epidemiológico Volume 46 - nº 37 - 2015 - Situação epidemiológica de ocorrência de microcefalias no Brasil, 2015. Available from: http://portalsaude.saude. gov.br/images/pdf/2015/dezembro/02/2015-046---Microcefalia----02. 12.15.pdf. Accessed May 2, 2016

41. Calvet GA, Aguiar RS, Melo AS, et al. Detection and sequencing of Zika virus from amniotic fluid of fetuses with microcephaly in Brazil: a case study. Lancet Infect Dis. 2016;16(6):653-660.
42. Oliveira Melo AS, Malinger G, Ximenes R, Szejnfeld PO, Alves Sampaio S, Bispo de Filippis AM. Zika virus intrauterine infection causes fetal brain abnormality and microcephaly: tip of the iceberg? Ultrasound Obstet Gynecol. 2016;47(1):6-7.

43. Brazil 2015 [webpage on the Internet]. Boletim Epidemiológico Volume 46 - no 37 - 2015 - Situação epidemiológica de ocorrência de microcefalias no Brasil, 2015. Available from: http://portalsaude. saude.gov.br/images/pdf/2015/novembro/30/Microcefalia-2-boletim. pdf. Accessed May 2, 2016.

44. Schuler-Faccini L, Ribeiro EM, Feitosa IM, et al. Possible association between Zika virus infection and microcephaly - Brazil, 2015. MMWR Morb Mortal Wkly Rep. 2016;65(3):59-62.

45. Mlakar J, Korva M, Tul N, et al. Zika virus associated with microcephaly. N Engl J Med. 2016;374(10):951-958.

46. Martines RB, Bhatnagar J, Keating MK, et al. Notes from the field: evidence of Zika virus infection in brain and placental tissues from two congenitally infected newborns and two fetal loses-Brazil, 2015. MMWR Morb Mortal Wkly Rep. 2016;65(6):159-160.

47. Sarno M, Sacramento GA, Khouri R, et al. Zika virus infection and stillbirths: a case of hydrops fetalis, hydranencephaly and fetal demise. PLoS Negl Trop Dis. 2016;10(2):e0004517.

48. Driggers RW, Ho CY, Korhonen EM, et al. Zika virus infection with prolonged maternal viremia and fetal brain abnormalities. NEngl J Med. 2016;374(22):2142-2151.

49. Meaney-Delman D, Hills SL, Williams C, et al. Zika virus infection among U.S. pregnant travelers - August 2015-February 2016. MMWR Morb Mortal Wkly Rep. 2016;65(8):211-214.

50. Brasil P, Pereira JP Jr, Raja Gabaglia C, et al [webpage on the Internet]. Zika virus infection in pregnant women in Rio de Janeiro - preliminary report. $N$ Engl J Med. 2016. Available from: www.nejm.org/doi/ full/10.1056/NEJMoa1602412. Accessed April 29, 2016.

51. Hazin AN, Poretti A, Cruz DD, et al. Computed tomographic findings in microcephaly associated with Zika virus. N Engl J Med. 2016; 374(22):2193-2195.

52. Aragao MFV, van der Linden V, Brainer-Lima AM, et al. Clinical features and neuroimaging (CT and MRI) findings in presumed Zika virus related congenital infection and microcephaly: retrospective case series study. BMJ. 2016;353:i1901.

53. Cavalheiro S, Lopez A, Serra S, et al. Microcephaly and Zika virus: neonatal neuroradiological aspects. Childs Nerv Syst. 2016;32(6): 1057-1060.

54. Werner H, Fazecas T, Guedes B, et al. Intrauterine Zika virus infection and microcephaly: perinatal imaging correlations with 3D virtual physical models. Ultrasound Obstet Gynecol. 2016;47(5):657-660.

55. Brazil. Ministério da Saúde [webpage on the Internet]. Protocolo de Vigilância a Ocorrência de Microcefalia e/ou Alterações do Sistema Nervoso Central. Brasília; 2016. Disponível em: http://combateaedes. saude.gov.br/images/sala-de-situacao/Microcefalia-Protocolo-devigilancia-e-resposta-10mar2016-18h.pdf. Accessed March 21, 2016.

56. Cauchemez S, Besnard M, Bompard P, et al. Association between Zika virus and microcephaly in French Polynesia, 2013-2015: a retrospective study. Lancet. 2016;387(10033):2125-2132.

57. Johansson MA, Mier-Y-Teran-Romero L, Reefhuis J, Gilboa SM, Hills SL. Zika and the risk of microcephaly. N Engl J Med. Epub 2016 May 25.

58. Besnard M, Eyrolle-Guignot D, Guillemette-Artur P, et al. Congenital cerebral malformations and dysfunction in fetuses and newborns following the 2013 to 2014 Zika virus epidemic in French Polynesia. Euro Surveill. 2016;21(13).

59. Guillemette-Artur P, Besnard M, Eyrolle-Guignot D, Jouannic JM, Garel C. Prenatal brain MRI of fetuses with Zika virus infection. Pediatr Radiol. 2016;46(7):1032-1039.

60. De Paula Freitas B, de Oliveira Dias JR, Prazeres J, et al. Ocular findings in infants with microcephaly associated with presumed Zika virus congenital infection in Salvador, Brazil. JAMA Ophthalmol. 2016;134(5):529-535. 
61. Ventura CV, Maia M, Ventura BV, et al. Ophthalmological findings in infants with microcephaly and presumable intra-uterus Zika virus infection. Arq Bras Oftalmol. 2016;79(1):1-3.

62. World Health Organization [webpage on the Internet]. Assessment of infants with microcephaly in the context of Zika virus - Interim Guidance - 4 March 2016 [Internet]. Genebra; 2016. Available from: http://apps.who.int/iris/bitstream/10665/204475/1/WHO_ZIKV_ MOC_16.3_eng.pdf?ua=1. Accessed April 23, 2016.

63. Ministério da Saúde, Secretaria de Vigilância em Saúde, Departamento de Vigilância das Doenças Transmissíveis [webpage on the Internet]. Protocolo de vigilância e resposta à ocorrência de microcefalia relacionada à infecção pelo vírus Zika/Ministério da Saúde, Secretaria de Vigilância em Saúde, Departamento de Vigilância das Doenças Transmissíveis - Brasília: Ministério da Saúde, 2016. Available from: http:// combateaedes.saude.gov.br/images/sala-de-situacao/MicrocefaliaProtocolo-de-vigilancia-e-resposta-10mar2016-18h.pdf. Accessed May 15, 2016.

64. WHO Multicentre Growth Reference Study Group [webpage on the Internet]. WHO Child Growth Standards: Head Circumference-forAge, Arm Circumference-for-Age, Triceps Skinfold-for-Age and Subscapular Skinfold-for-Age: Methods and Development. Geneva: World Health Organization; 2007:217. Available from: http:/www.who.int/ childgrowth/standards/second_set/technical_report_2/en/. Accessed April 29, 2016.

65. Kleber de Oliveira W, Cortez-Escalante J, De Oliveira WT, et al. Increase in reported prevalence of microcephaly in infants born to women living in areas with confirmed Zika virus transmission during the first trimester of pregnancy - Brazil, 2015. MMWR Morb Mortal Wkly Rep. 2016;65:242-247.

66. Soares de Araújo JS, Regis CT, Gomes RGS, et al. Microcephaly in northeast Brazil: a review of 16208 births between 2012 and 2015 [Submitted]. Bull World Health Organ. Epub 2016 Feb 4.

67. Simmins CH Jr. Establishing base levels of microcephaly in Brazil prior to the arrival of Zika viral illnesses [submitted]. Bull World Health Organ. Epub 2016 Feb 8.

68. Latin American Colaborative Study of Congenital Malformations [webpage on the Internet]. ECLAMC Final Document. Available from: http://www.eclamc.org/eng/index.php. Accessed May 2, 2016.

69. Nunes ML, Carlini CR, Marinowic D, et al. Microcephaly and Zika virus: a clinical and epidemiological analysis of the current outbreak in Brazil. J Pediatr (Rio J). 2016;92(3):230-240.

70. Barreto ML, Barral-Netto M, Stabeli R, et al. Zika virus and microcephaly in Brazil: a scientific agenda. Lancet. 2016;387(10022):919-921.

71. Rasmussen SA, Jamieson DJ, Honein MA, Petersen LR. Zika virus and birth defects - reviewing the evidence for causality. N Engl J Med.2016; 374(20):1981-1987.

72. Miranda-Filho Dde B, Martelli CM, Ximenes RA, et al. Initial description of the presumed congenital Zika syndrome. Am J Public Health. 2016; 106(4):598-600.
73. Center for Disease Control [webpage on the Internet]. Zika and Pregnancy; 2015. Available from: http://www.cdc.gov/zika/pregnancy/ question-answers.html. Accessed April 29, 2016.

74. World Health Organization [webpage on the Internet]. Zika virus disease, yellow fever, Ebola virus disease: situation report-Issue Date: 28-Apr-2016. Available from: http://www.who.int/iris/handle/10665/205686. Accessed April 29, 2016.

75. Tang H, Hammack C, Ogden SC, et al. Zika virus infects human cortical neural progenitors and attenuates their growth. Cell Stem Cell. 2016;18(5): 587-590.

76. Garcez PP, Loiola EC, Madeiro da Costa R, et al. Zika virus impairs growth in human neurospheres and brain organoids. Science. 2016;352(6287): 816-818.

77. Bell TM, Field EJ, Narang HK. Zika virus infection of the central nervous system of mice. Arch Gesamte Virusforsch. 1971;35(2):183-193.

78. Way JH, Bowen ET, Platt GS. Comparative studies of some African arboviruses in cell culture and in mice. J Gen Virol. 1976;30(1):123-130.

79. Lazear HM, Govero J, Smith AM, et al. A mouse model of Zika virus pathogenesis. Cell Host Microbe. 2016;19(5):720-730.

80. Rossi SL, Tesh RB, Azar SR, et al. Characterization of a novel murine model to study Zika virus. Am J Trop Med Hyg. 2016;94(6): 1362-1369.

81. Hamel R, Dejarnac O, Wichit S, et al. Biology of Zika virus infection in human skin cells. J Virol. 2015;89(17):8880-8896.

82. Oehler E, Watrin L, Larre P, et al. Zika virus infection complicated by Guillain-Barré syndrome - case report, French Polynesia, 2013. Euro Surveill. 2014;19(9):pii:20720.

83. Cao-Lormeau VM, Blake A, Mons S, et al. Guillain-Barré Syndrome outbreak associated with Zika virus infection in French Polynesia: a case-control study. Lancet. 2016;387(10027):1531-1539.

84. van den Berg B, Walgaard C, Drenthen J, Fokke C, Jacobs BC, van Doorn PA. Guillain-Barré syndrome: pathogenesis, diagnosis, treatment and prognosis. Nat Rev Neurol. 2014;10(8):469-482.

85. Smith DS, Mackenzie J. Zika virus and Guillain-Barre syndrome: another viral cause to add to the list. Lancet. 2016;387:1486-1488.

86. Carod-Artal FJ. Epidemiology and neurological complications of infection by the Zika virus: a new emerging neurotropic virus. Rev Neurol. 2016;62(7):317-328

87. Carod-Artal FJ, Wichmann O, Farrar J, Gascón J. Neurological complications of dengue virus infection. Lancet Neurol. 2013;12(9):906-919.

88. Mécharles S, Herrmann C, Poullain P, et al. Acute myelitis due to Zika virus infection. Lancet. 2016;387(10026):1481.

89. Ferreira MLB. Neurologic Manifestations of Arboviruses in the Epidemic in Pernambuco, Brazil. In: American Academy of Neurology Annual Meeting; 2016.
Neuropsychiatric Disease and Treatment

\section{Publish your work in this journal}

Neuropsychiatric Disease and Treatment is an international, peerreviewed journal of clinical therapeutics and pharmacology focusing on concise rapid reporting of clinical or pre-clinical studies on a range of neuropsychiatric and neurological disorders. This journal is indexed on PubMed Central, the 'PsycINFO' database and CAS,

\section{Dovepress}

and is the official journal of The International Neuropsychiatric Association (INA). The manuscript management system is completely online and includes a very quick and fair peer-review system, which is all easy to use. Visit http://www.dovepress.com/testimonials.php to read real quotes from published authors. 